\title{
Estudo do comportamento hidrológico do Rio São Francisco e seus principais afluentes ${ }^{1}$
}

\author{
Silvio B. Pereira ${ }^{2}$, Fernando F. Pruski ${ }^{3}$, Demetrius D. da Silva $^{3}$ \& Márcio M. Ramos ${ }^{3}$
}

\begin{abstract}
RESUMO
A Bacia do São Francisco possui 36 afluentes mais importantes, dos quais 19 são perenes, cujas áreas de drenagem, com exceção do Rio Verde Grande, se situam na região da bacia não abrangida pelo Polígono das Secas, representando 50\% da área total da bacia. Analisou-se, neste trabalho, o comportamento hidrológico do Velho Chico e seus principais afluentes pertinentes aos dados anuais de precipitação média, vazão específica média e coeficiente de deságüe. Os resultados obtidos permitiram as seguintes conclusões: as variáveis hidrológicas estudadas apresentaram valores médios no segundo período superiores aos do primeiro; os afluentes estudados, que representam 46,3\% da área da bacia, contribuem com 81 \% da sua vazão, no período sem a influência dos reservatórios de acumulação; as sub-bacias com as maiores contribuições para a formação da vazão do Rio São Francisco são as dos Rios Paracatu, Grande e Velhas.
\end{abstract}

Palavras-chave: precipitação média, vazão média, disponibilidade hídrica

\section{Study of the hydrological behavior of São Francisco River and its main tributaries}

\begin{abstract}
The São Francisco Basin has 36 major tributaries, of which 19 are perennial. The areas of drainage of these tributaries, except for the Raverde Livarde, are located in the area of the basin not included in the drought region, representing $50 \%$ of the total area of the basin. In this study the hydrological behavior of the São Francisco River and its main tributaries was analyzed in relation to the annual data of mean precipitation, mean specific flow and outflow coefficient. The obtained results lead the following conclusions: the studied hydrological variables presented mean values in the second period superior to those of the first one; the studied tributaries that represent $46.3 \%$ of the basin area contribute $81 \%$ of its flow for the period without the influence of the reservoir accumulation; the sub-basins that present the largest contributions for the formation of the flow of São Francisco River are the ones of the Rivers Paracatu, Grande and Velhas.
\end{abstract}

Key words: mean rainfall, mean discharge, water availability

\footnotetext{
1 Parte da Tese de Doutorado do primeiro autor apresentada à UFV

2 Faculdade de Ciências Agrárias/UFGD, CEP 79804-970, CP 533, Dourados, MS. Fone: (67) 3411-3854. E-mail: sbueno@ufgd.edu.br

3 DEA/UFV, Viçosa, MG. Fone: (31) 3899-1912. E-mail: ffpruski@ufv.br; david@ufv.br; mmramos@ufv.br
} 


\section{INTRODUÇÃO}

A Bacia do São Francisco, com área de drenagem de $639.219 \mathrm{~km}^{2}$, se estende pelos Estados de Minas Gerais, Bahia, Goiás, Pernambuco, Sergipe e Alagoas, além do Distrito Federal, representando 7,5\% do território brasileiro (ANA, 2002) e, devido à sua extensão e aos diferentes ambientes percorridos, ela se divide em quatro unidades fisiográficas: na região do Alto São Francisco, correspondente a 19\% da área da bacia, que vai da nascente até a cidade de Pirapora, MG; no Médio São Francisco, que se estende de Pirapora a Remanso, BA, correspondente a 55\% da bacia; no Submédio São Francisco, de Remanso até Paulo Afonso, BA (24\% da bacia) e no Baixo São Francisco, que vai de Paulo Afonso até a foz (7\% da bacia).

A Bacia do São Francisco possui 36 afluentes mais importantes, dentre os quais apenas 19 são perenes destacando-se, pela margem direita, os Rios Pará, Paraopeba, Velhas e Verde Grande e, pela margem esquerda, os Rios Abaeté, Paracatu, Urucuia, Pandeiros, Carinhanha, Corrente e Grande. As áreas de drenagem desses afluentes, com exceção do Rio Verde Grande, se situam na região não abrangida pelo Polígono das Secas, representando cerca de 50\% da área total da bacia (ANEEL, 1998).

O clima se caracteriza pela ocorrência de temperaturas de mediana a elevada durante quase todo o ano, com temperatura média anual variando de 18 a $27^{\circ} \mathrm{C}$ e, ainda, por um baixo índice de nebulosidade com grande incidência de radiação solar e pela existência de duas estações bem distintas, ou seja, uma seca e outra chuvosa (Brasil, 2003).

Em função das elevadas temperaturas e dos baixos índices de nebulosidade, a evapotranspiração potencial é muito alta, principalmente na região do Submédio São Francisco onde algumas estações registram valores de até $3.000 \mathrm{~mm} \mathrm{ano}^{-1}$. A elevada evapotranspiração potencial não compensada pelas chuvas afeta expressivamente o balanço hídrico dos solos (Ioris, 2001).

O crescimento da exploração econômica na Bacia do São Francisco, sobretudo pela agricultura irrigada, foi intensificada a partir de 1976 (ONS, 2004), com destaque para as regiões do Submédio e Baixo São Francisco (Rodriguez \& Holtz, 2003).

Além da irrigação, o São Francisco tem seu potencial hidrelétrico bastante aproveitado, com diversas usinas hidrelétricas instaladas ao longo da bacia. Em 1973, a Companhia Hidro Elétrica do São Francisco (CHESF) começou a construção do reservatório de Sobradinho, cujo lago, formado em 1979 e com superfície de $4.214 \mathrm{~km}^{2}$, é um dos maiores lagos artificiais do mundo, servindo como reservatório de regularização plurianual. O reservatório de Sobradinho localiza-se no Submédio São Francisco, a aproximadamente $40 \mathrm{~km}$ à montante das cidades de Juazeiro e Petrolina, cuja potência instalada é de 1.050 MW (Correia \& Dias, 2003).

Em virtude da Bacia do São Francisco representar um importante indutor do desenvolvimento dos diversos Estados por ele banhado, o conhecimento do seu comportamento hidrológico é de extremo valor para subsidiar a tomada de decisões na gestão de recursos hídricos, uma vez que permitirá conhecer a disponibilidade deste recurso, possibilitando identificar as áreas em que este recurso é ou poderá ser escasso.

Com base neste enfoque se propõe, com o presente trabalho, estudar o comportamento hidrológico do Rio São Francisco e seus principais afluentes, pertinentes aos dados de precipitação média anual, vazão específica média anual e coeficiente de deságüe.

\section{MATERIAL E MÉTODOS}

Para realização do estudo analisaram-se os dados consistidos de 178 estações pluviométricas e 12 estações fluviométricas pertencentes à rede hidrometeorológica da Agência Nacional de Águas (ANA). Dentre as estações fluviométricas estudadas, uma está localizada próximo à foz do Rio São Francisco e as demais correspondem às estações localizadas na posição mais à jusante de cada um dos afluentes estudados.

Na Figura 1 estão apresentadas as principais sub-bacias estudadas e suas áreas de drenagem, além das proporções da área em relação à da Bacia do São Francisco e se tem, na Tabela 1, as estações fluviométricas, a latitude, longitude, área de drenagem, o rio em que se situam e a região fisiográfica a que pertencem.

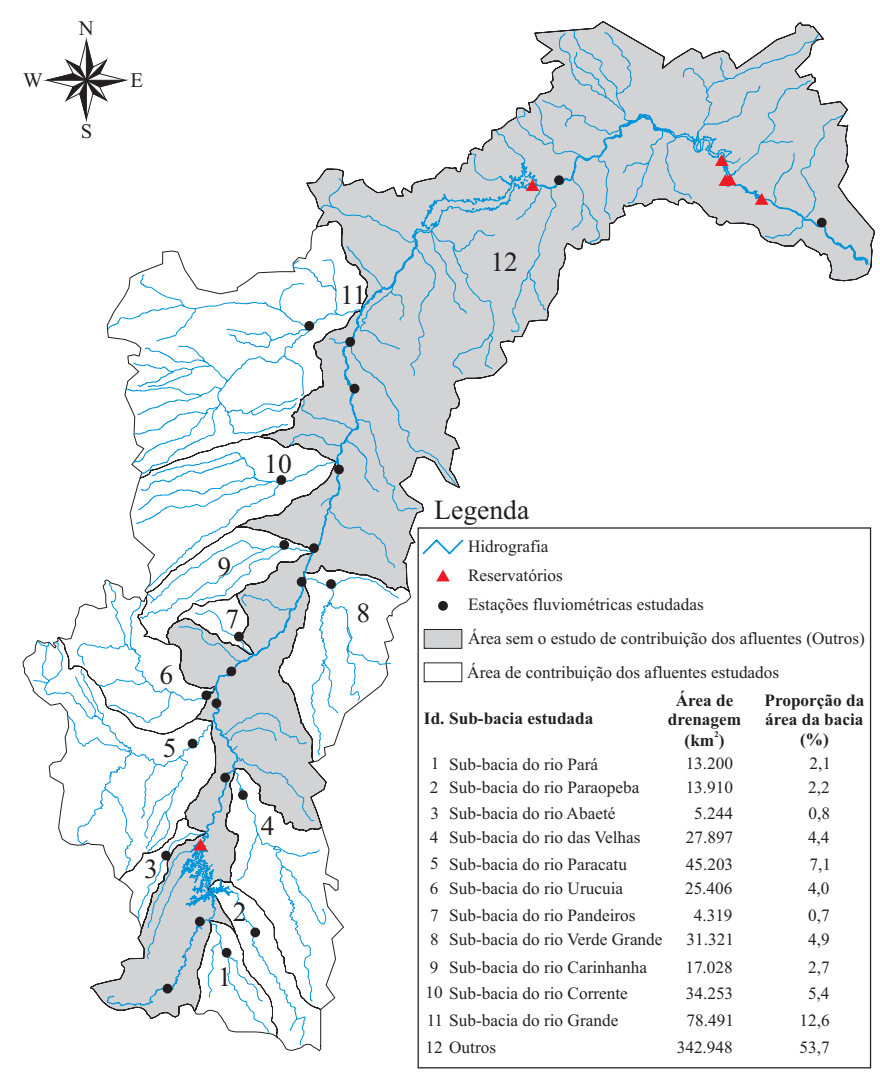

Figura 1. Principais sub-bacias do Rio São Francisco, suas áreas de drenagem, proporções em relação à bacia e localização das estações fluviométricas estudadas 
Tabela 1. Estações fluviométricas selecionadas para o estudo, coordenadas geográficas, áreas de drenagem, rios e regiões a que pertencem

\begin{tabular}{|c|c|c|c|c|}
\hline Estação & Latitude Longitude & $\begin{array}{c}\text { Área de } \\
\text { drenagem } \\
\left(\mathrm{km}^{2}\right)\end{array}$ & Rio & Região \\
\hline Velho da Taipa & $19^{\circ} 41^{\prime} 38^{\prime \prime} 44^{\circ} 55^{\prime} 51^{\prime \prime}$ & 7.350 & Pará & \multirow{4}{*}{ Alto } \\
\hline Ponte da Taquara & $19^{\circ} 25^{\prime} 23^{\prime \prime} 44^{\circ} 32^{\prime} 52^{\prime \prime}$ & 8.720 & Paraopeba & \\
\hline Porto do Passarinho & $18^{\circ} 24^{\prime} 09^{\prime \prime} 45^{\circ} 44^{\prime} 12^{\prime \prime}$ & 4.330 & Abaeté & \\
\hline Várzea da Palma & $17^{\circ} 35^{\prime} 39^{\prime \prime} 44^{\circ} 42^{\prime} 51^{\prime \prime}$ & 25.940 & Velhas & \\
\hline Porto Alegre & $16^{\circ} 54^{\prime} 25^{\prime \prime} 45^{\circ} 22^{\prime} 57^{\prime \prime}$ & 40.300 & Paracatu & \multirow{7}{*}{ Médio } \\
\hline Barra do Escuro & $16^{\circ} 16^{\prime} 07^{\prime \prime} 45^{\circ} 14^{\prime} 16^{\prime \prime}$ & 24.658 & Urucuia & \\
\hline Usina do Pandeiros & $15^{\circ} 28^{\prime} 59^{\prime \prime} 44^{\circ} 46^{\prime} 02^{\prime \prime}$ & 3.812 & Pandeiros & \\
\hline Boca da Caatinga & $14^{\circ} 47^{\prime} 05^{\prime \prime} 43^{\circ} 32^{\prime} 22^{\prime \prime}$ & 28.321 & $\begin{array}{l}\text { Verde } \\
\text { Grande }\end{array}$ & \\
\hline Juvenília & $14^{\circ} 15^{\prime} 46^{\prime \prime} 44^{\circ} 09^{\prime} 39^{\prime \prime}$ & 15.600 & Carinhanha & \\
\hline Santa Maria da Vitória & $13^{\circ} 24^{\prime} 00^{\prime \prime} 44^{\circ} 12^{\prime} 00^{\prime \prime}$ & 29.570 & Corrente & \\
\hline Boqueirão & $11^{\circ} 20^{\prime} 38^{\prime \prime} 43^{\circ} 49^{\prime} 42^{\prime \prime}$ & 68.540 & Grande & \\
\hline Traipu & $09^{\circ} 58^{\prime} 17^{\prime \prime} 37^{\circ} 00^{\prime} 17^{\prime \prime}$ & 622.600 & $\begin{array}{c}\text { São } \\
\text { Francisco }\end{array}$ & Baixo \\
\hline
\end{tabular}

Com base na análise dos dados disponíveis optou-se por selecionar o período-base de 1950 a 2000. Após a análise dos dados hidrológicos, àqueles inexistentes ou considerados inconsistentes foram atribuídas falhas para posterior preenchimento. O preenchimento de falhas foi realizado por meio de correlações, segundo critérios consagrados de escolha de bases para as regressões.

Na análise da distribuição espacial das precipitações anuais ao longo da bacia, utilizou-se o método das isoietas e, para o cálculo da precipitação média nas áreas de drenagem das 12 estações fluviométricas estudadas, o método do Polígono de Thiessen, segundo metodologias descritas por Tucci (2000).

A vazão média anual de longa duração foi calculada utilizando-se a média das vazões médias anuais e a vazão específica média de longa duração foi obtida pela divisão dos dados de vazão média anual pela área de drenagem da estação fluviométrica considerada.

Realizou-se, para as estações localizadas nos afluentes do São Francisco, a regionalização da vazão média a partir do método de razão de área de drenagem (Eq. 1), proposta por Stendinger et al. (1992), citados por Chaves et al. (2002). Este método é usado, comumente, no cálculo de vazões regionais, visando à estimativa das vazões nas seções de deságüe das sub-bacias no Rio São Francisco.

$$
\mathrm{Q}_{\mathrm{r}}=\left(\frac{\mathrm{A}_{\mathrm{y}}}{\mathrm{A}_{\mathrm{x}}}\right) \mathrm{Q}_{\mathrm{rp}}
$$

em que

$\mathrm{Q}_{\mathrm{r}}$ - vazão de referência em um ponto da bacia, $\mathrm{m}^{3} \mathrm{~s}^{-1}$

$\mathrm{Q}_{\mathrm{rp}}$ - vazão de referência em um posto fluviométrico próximo, $\mathrm{m}^{3} \mathrm{~s}^{-1}$

$\mathrm{A}_{\mathrm{x}}$ - área de drenagem da seção de vazão conhecida, $\mathrm{km}^{2}$

$\mathrm{A}_{\mathrm{y}}$ - área de drenagem da seção de interesse, $\mathrm{km}^{2}$

Conhecidas a precipitação média, a vazão média anual e a área de drenagem de cada um dos afluentes estudados, calculou-se a proporção de contribuição de cada um dos afluentes; para tanto, propuseram-se os conceitos de contribuições potencial e real, visando à identificação da proporção de contribuição de cada um dos afluentes para a formação da vazão do Rio São Francisco.

A contribuição potencial é definida pela relação entre o volume precipitado na área de drenagem de cada afluente e o volume precipitado na área de drenagem da Bacia do São Francisco, ou seja, é a contribuição que o afluente apresentaria para a formação da vazão do Rio São Francisco se toda a precipitação fosse convertida em escoamento, calculada pela equação:

$$
\mathrm{C}_{\mathrm{p}}=\frac{\mathrm{V}_{\mathrm{pa}}}{\mathrm{V}_{\mathrm{pb}}} 100
$$

em que

$\mathrm{C}_{\mathrm{p}}$ - contribuição potencial, \%

$\mathrm{V}_{\mathrm{pa}}$ - volume precipitado na área de drenagem do afluente estudado, $\mathrm{m}^{3}$

$\mathrm{V}_{\mathrm{pb}}$ - volume precipitado na área de drenagem da bacia, $\mathrm{m}^{3}$

Define-se a contribuição real pela relação existente entre o volume médio escoado na seção de deságüe do afluente no Rio São Francisco e o volume médio escoado na foz do São Francisco, esta representativa da contribuição que cada afluente apresenta para a formação da vazão do Rio São Francisco refletindo, neste caso, as perdas ocorridas por evapotranspiração, representadas pela equação:

$$
\mathrm{C}_{\mathrm{r}}=\frac{\mathrm{V}_{\mathrm{ea}}}{\mathrm{V}_{\mathrm{eb}}} 100
$$

em que

$$
\begin{aligned}
\mathrm{C}_{\mathrm{r}}- & \text { contribuição real, \% } \\
\mathrm{V}_{\mathrm{ea}}- & \text { volume médio escoado na seção de deságüe do } \\
& \text { afluente, } \mathrm{m}^{3} \\
\mathrm{~V}_{\mathrm{eb}}- & \text { volume médio escoado na foz da bacia do São } \\
& \text { Francisco, } \mathrm{m}^{3}
\end{aligned}
$$

Para representação da área de drenagem da Bacia do São Francisco se utilizou a estação Traipu (estação localizada mais a foz da bacia), com área de drenagem de 622.600 km² representando, portanto, 97,4\% da área da bacia.

Na área de drenagem não abrangida pelos afluentes estudados correspondente a $342.948 \mathrm{~km}^{2}$ e que representa $53,7 \%$ da área da Bacia do São Francisco, tanto o volume precipitado como o volume escoado foram obtidos pela diferença entre o valor correspondente à área de drenagem da Bacia do São Francisco, representada pela estação Traipu e a soma dos valores de todas as sub-bacias estudadas, descrita pela equação:

$$
\mathrm{V}_{\mathrm{h}^{*}}=\mathrm{V}_{\mathrm{hb}}-\sum \mathrm{V}_{\mathrm{ha}}
$$

em que

$\mathrm{V}_{\mathrm{h}^{*}}$ - variável hidrológica na área de drenagem não abrangida pelos afluentes estudados

$\mathrm{V}_{\mathrm{hb}}$ - variável hidrológica na bacia

$\mathrm{V}_{\text {ha }}$ - variável hidrológica nos afluentes estudados

O coeficiente de deságüe foi obtido pela razão entre o 
volume que escoa pela seção de deságüe considerada e o volume total precipitado.

Realizou-se, previamente, o estudo de análise de estacionariedade considerando-se os períodos de 1950 a 1976 e 1979 a 2000, que correspondem aos períodos anterior e posterior ao enchimento do reservatório de Sobradinho, e do expressivo crescimento econômico evidenciado na Bacia do São Francisco a fim de identificar alterações ocorridas no comportamento das vazões médias. Os testes para verificação da identidade de variâncias e de médias, foram os de Fisher e Student, respectivamente, sendo a aplicação realizada conforme a metodologia proposta por Euclydes et al. (1999).

\section{RESULTADOS E DISCUSSÃO}

Por meio da análise de estacionariedade identificou-se a não-estacionariedade para a estação à jusante de Sobradinho, sendo facilmente justificada pelas grandes alterações ocorridas nesta região da bacia, seja pela formação do reservatório ou pelo grande desenvolvimento ocorrido na bacia, a partir da década de 1970, tendo a irrigação, segmento com maior requerimento de água, como um dos principais indutores deste desenvolvimento.

Nas estações de montante, entretanto, também se evidencia um comportamento não-estacionário para os períodos de 1950 a 1976 e 1979 a 2000, mesmo não havendo os efeitos de regularização mencionados para as estações de jusante, fato este justificado pelo expressivo aumento da precipitação no segundo período analisado. Com base nesta análise

A.
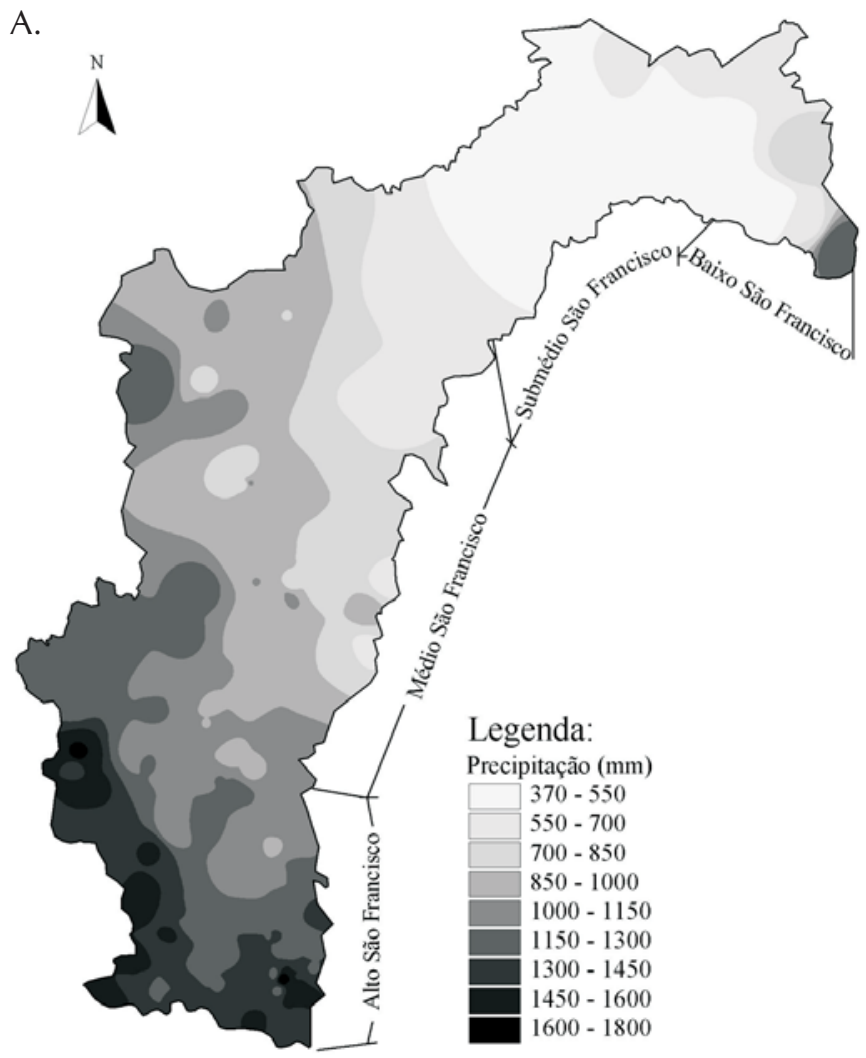

consideraram-se, para o estudo do comportamento hidrológico do Rio São Francisco e seus principais afluentes, os períodos de 1950 a 1976 e 1979 a 2000.

Apresenta-se, na Figura 2, para a Bacia do São Francisco, a distribuição da precipitação média anual considerando-se os períodos de 1950 a 1976 e de 1979 a 1999. A precipitação média nesses períodos foi maior na região de cabeceira, decrescendo em direção à foz até as proximidades do limite entre o Submédio e o Baixo São Francisco; a partir daí, ocorre um acentuado aumento da precipitação em decorrência da influência oceânica no regime pluviométrico.

As precipitações observadas variaram de 390 a $1.710 \mathrm{~mm}$ no primeiro período analisado e de 370 a $1.800 \mathrm{~mm}$ no segundo. Constatou-se, no Alto e Médio São Francisco, aumento das precipitações médias anuais do primeiro para o segundo período, principalmente na área de cabeceira e na margem esquerda da Bacia do São Francisco. No Submédio e Baixo, o comportamento foi oposto sendo, em geral, a precipitação no segundo período, um pouco inferior à do primeiro.

A Figura 3 representa as precipitações médias anuais nas áreas de drenagem dos principais afluentes do São Francisco e a precipitação média na bacia, representada pela estação Traipu; apenas a Sub-Bacia do Verde Grande e a área não abrangida pelos afluentes estudados apresentaram precipitações menores que a evidenciada na bacia. A precipitação média no segundo período foi sempre maior que a do primeiro, sendo a máxima variação na Sub-Bacia do Rio Corrente $(14,4 \%)$ e a mínima na do Paracatu $(0,5 \%)$.

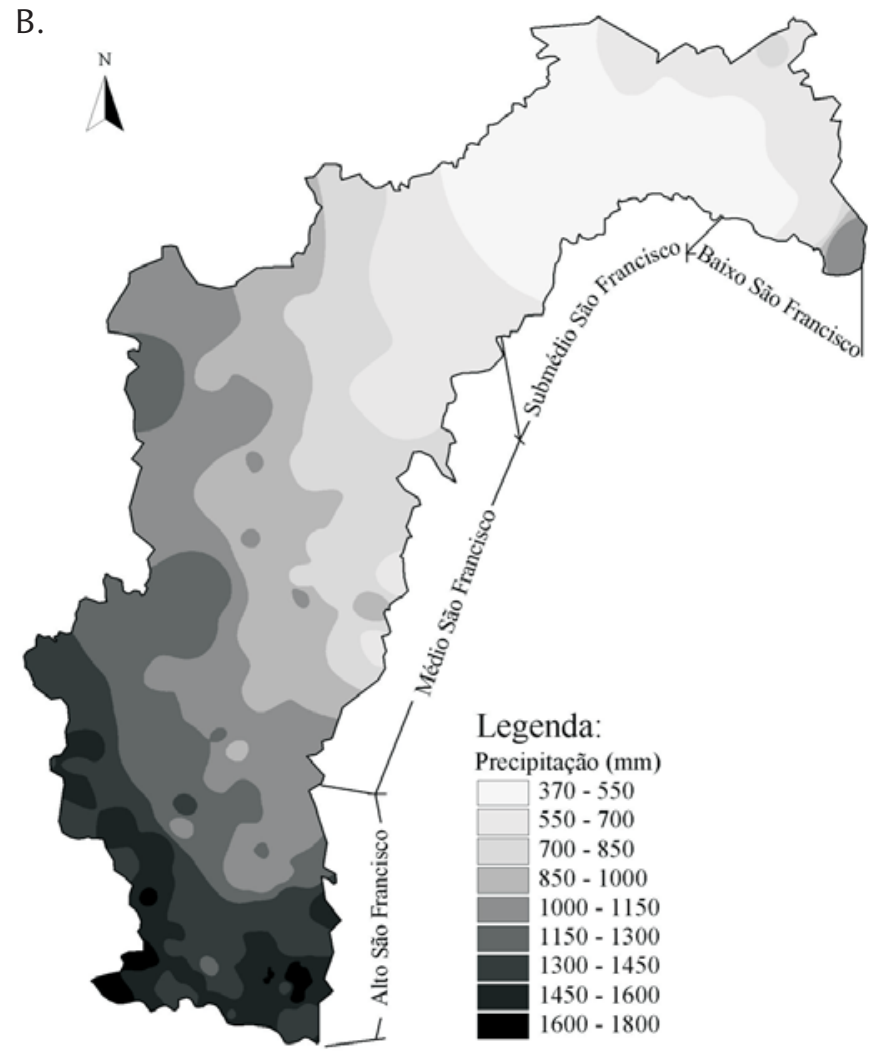

Figura 2. Precipitação média anual na Bacia do São Francisco, considerando-se os períodos de 1950 a 1976 (A) e de 1979 a 1999 (B) 


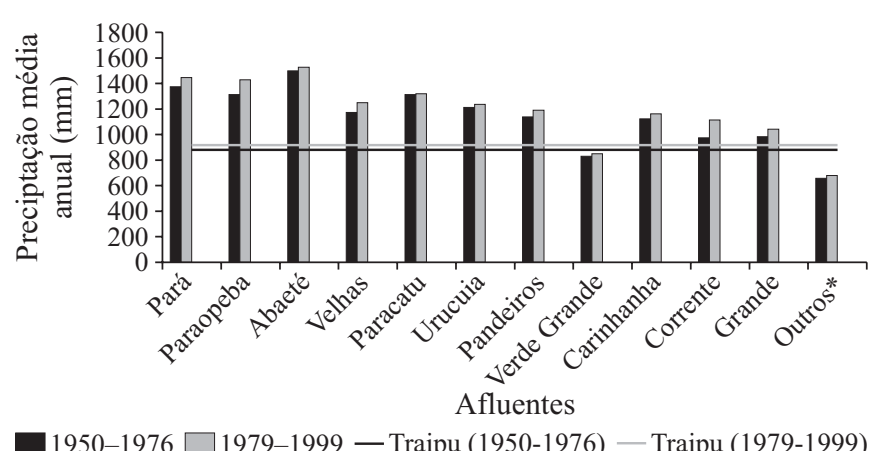

(*) Contribuição da área de drenagem não abrangida pelos afluentes estudados e 0 efeito das ações antrópicas

Figura 3. Precipitação média anual nas áreas de drenagem dos principais afluentes e na área de drenagem da Bacia do São Francisco, representada pela estação Traipu, considerando-se os períodos de 1950 a 1976 e de 1979 a 1999

Na análise da contribuição potencial de cada um dos afluentes estudados (Figura 4), evidencia-se que as maiores proporções de contribuição são as dos Rios Grande e Paracatu. Embora não sejam as sub-bacias com as maiores precipitações médias são, no entanto, as que apresentam as maiores áreas de drenagem, com $78.491 \mathrm{~km}^{2}$ e $45.203 \mathrm{~km}^{2}$, respectivamente, fazendo com que os volumes precipitados nessas áreas sejam de maior magnitude.

Considerando-se o período de 1950 a 1976 (Figura 4A), verificou-se que a Sub-Bacia do Rio Grande, que representa 12,6\% da área de drenagem da Bacia do São Francisco, abrange a maior contribuição potencial (14,2\%), sendo a precipitação média nesta sub-bacia $12,5 \%$ superior à da bacia (Figura 3).

Na Sub-Bacia do Paracatu, que apresenta a segunda maior contribuição potencial (10,9\%), observa-se que sua área de drenagem representa apenas 7,3\% da área da Bacia do São Francisco mas indica uma precipitação média superior à da bacia, em 46,4\%. Em relação à Sub-Bacia do Grande, a Sub-Bacia do Paracatu mostra uma área equivalente a $57,6 \%$, sendo a contribuição potencial, entretanto, da ordem de 77,0\% daquela do Rio Grande.

Para a Sub-Bacia do Rio Verde Grande, cuja área representa 5,0\% da área da Bacia do Rio São Francisco, a contribuição potencial é de 4,8\% tendo em vista o fato da sua precipitação ser, menor que a precipitação média na Bacia do São Francisco; este comportamento também foi constatado na área não abrangida pelos afluentes estudados, que representa 53,7\% da área da bacia e uma contribuição potencial da ordem de $39,6 \%$.

Considerando-se o segundo período, verifica-se que as variações nas proporções das contribuições potenciais, em relação ao primeiro período, foram muito pequenas e estão diretamente relacionadas com as mudanças nas precipitações das diversas sub-bacias. Nas Sub-Bacias dos Rios Paracatu, Urucuia e Verde Grande e da área não abrangida pelas sub-bacias estudadas e apesar das precipitações também terem sido mais altas no segundo período, o aumento foi menor que o ocorrido na precipitação média da bacia, o que acarretou, portanto, decréscimo na proporção da contribuição potencial.
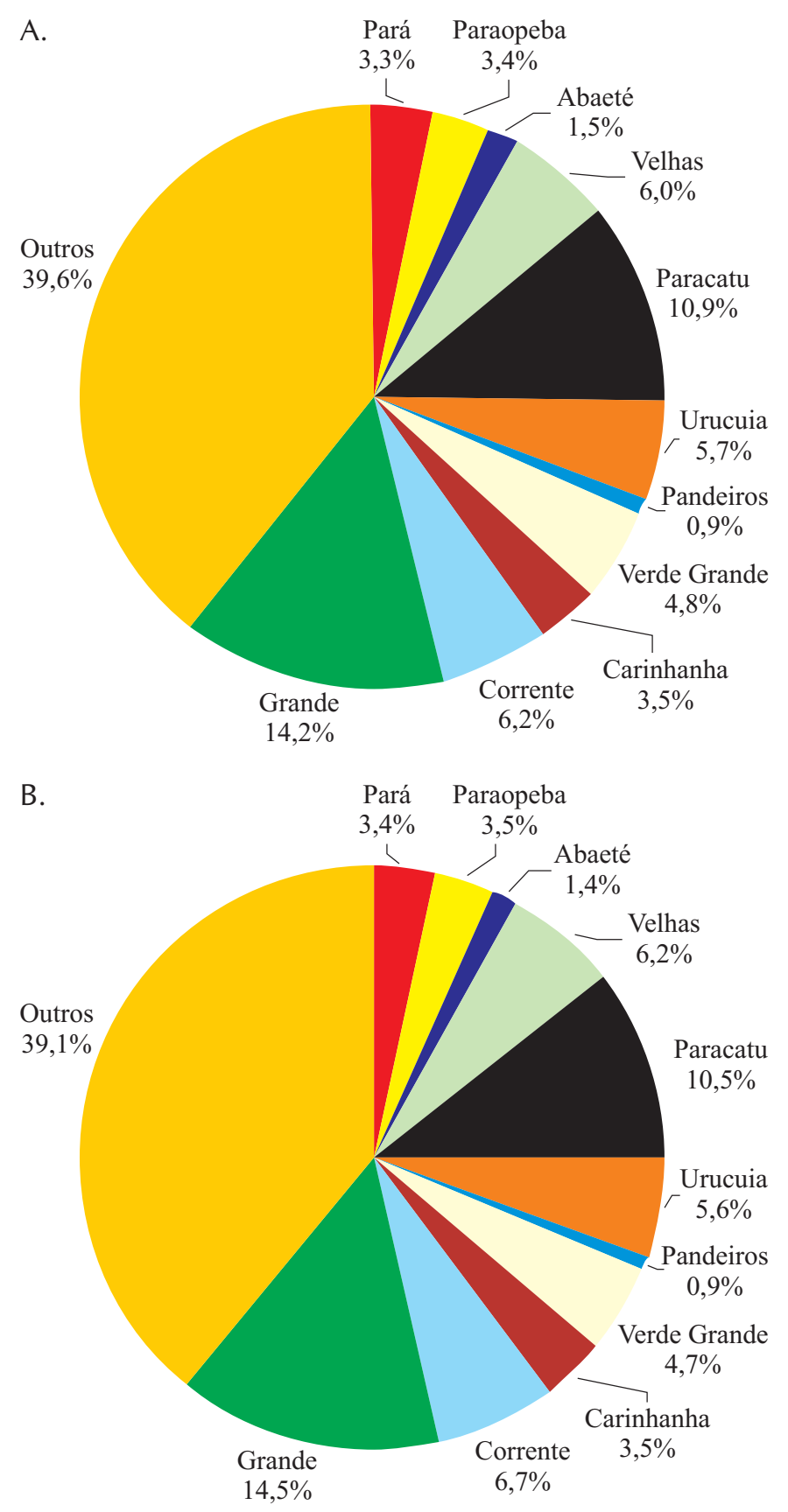

Figura 4. Proporção da contribuição potencial dos principais afluentes para com o Rio São Francisco, considerando-se os períodos de 1950 a 1976 (A) e de 1979 a 1999 (B)

Apresentam-se, na Figura 5, as vazões específicas médias de longa duração nos principais afluentes do Rio São Francisco e no próprio rio principal. As vazões específicas mais altas foram encontradas nas regiões de cabeceira da bacia, decorrentes das maiores precipitações evidenciadas nessas áreas.

As únicas sub-bacias que apresentaram vazões específicas expressivamente menores que a vazão específica média evidenciada na bacia, foram a do Verde Grande e aquelas correspondentes à área não abrangida pelos afluentes estudados, sendo estas as únicas regiões com precipitações médias nas suas áreas de drenagem inferiores à média evidenciada na Bacia do São Francisco. 


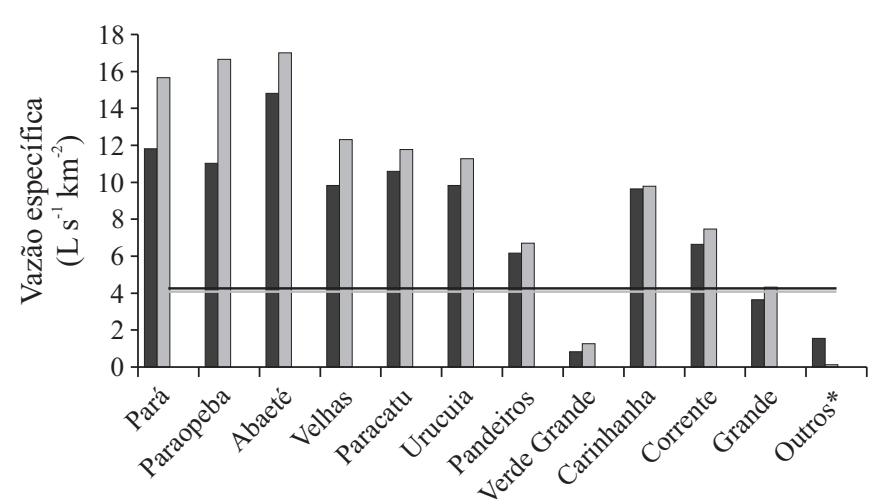

Afluentes

$\square$ 1950-1976 $\square 1979$ - 2000 — Traipu (1950-1976) — Traipu (1979-2000) (*) Contribuição da área de drenagem não abrangida pelos afluentes estudados e 0 efeito das ações antrópicas

Figura 5. Vazão específica média de longa duração nos principais afluentes e no Rio São Francisco, representada pela estação Traipu, considerandose os períodos de 1950 a 1976 e de 1979 a 2000

Na Sub-Bacia do Verde Grande e apesar da precipitação ter sido inferior à precipitação média na Bacia do São Francisco em apenas 5,7\% no período de 1950 a 1976 e 7,6\% no período de 1979 a 2000 (Figura 3), a redução da vazão específica em relação à média da bacia foi da ordem de 80,5 e 69,2\%, respectivamente (Figura 5).

Tendo em vista ser a precipitação média anual, na Sub-Bacia do Rio Verde Grande, correspondente a $830 \mathrm{~mm}$ no período de 1950 a 1976, muito inferior à evapotranspiração potencial, ocorre um déficit de água no solo muito grande, fazendo com que a maior parcela do total precipitado seja retida na camada superficial do solo; esta água, retida na camada explorada pelo sistema radicular das culturas, é posteriormente evapotranspirada, reduzindo a parcela da precipitação convertida em escoamento no rio. Comparando-se o comportamento observado no período de 1979 a 2000 com o do período de 1950 a 1976 conclui-se que, embora o aumento da precipitação fosse de apenas 2,3\%, o incremento do volume escoado foi de $53,7 \%$, ou seja, passou de $0,82 \mathrm{~L} \mathrm{~s}^{-1} \mathrm{~km}^{-2}$, relativo ao primeiro período, para $1,26 \mathrm{~L} \mathrm{~s}^{-1} \mathrm{~km}^{-2}$, referente ao segundo.

Mesmo com a intensificação do uso da água pela irrigação na Sub-Bacia do Verde Grande ocasionando, inclusive, a intermitência dos principais cursos d'água da região (ANA, 2002), não se constatou este efeito na vazão média de longa duração visto que no período de 1979 a 2000 (período de maior crescimento econômico na sub-bacia) se observou aumento da vazão específica. Rodriguez (2004) também constatou que, apesar da irrigação ter sido a maior responsável pela vazão consumida na Sub-Bacia do Paracatu, isto é, por até $93 \%$ do total consumido, a relação com a vazão média de longa duração apresentou pouca influência, sendo a maior percentagem dessa relação da ordem de 2,1\%.

Comportamento similar ao evidenciado no Verde Grande foi também constatado no período de 1950 a 1976, na área não abrangida pelos afluentes estudados, ou seja, 53,7\% da área da Bacia do São Francisco e onde a precipitação média também é muito inferior à evapotranspiração potencial. Com relação ao período de 1979 a 2000, verificou-se que a vazão específica foi menor que a do primeiro período estudado, fato este que pode ser entendido pelo motivo de que a construção e o enchimento dos reservatórios de acumulação (Sobradinho, Itaparica/Luiz Gonzaga, Moxotó, Paulo Afonso e Xingó) acarretaram expressiva evaporação dos reservatórios, o que ocasionou, portanto, a redução da vazão específica uma vez que a vazão média de longa duração dessas áreas foi quantificada pela diferença entre a vazão de Traipu e a soma das vazões correspondentes a todas as sub-bacias estudadas.

As maiores vazões específicas foram observadas na região do Alto São Francisco, as quais podem ser justificadas pelos fatos de: as precipitações serem as mais elevadas na bacia, chegando a atingir valores da ordem de $1.800 \mathrm{~mm}$; as evapotranspirações potenciais serem as mais baixas na bacia; e alta urbanização e impermeabilização dessas sub-bacias, tendo em vista a presença da região metropolitana de Belo Horizonte, nas Sub-Bacias dos Rios das Velhas e Paraopeba.

Analisando-se as diferenças ocorridas entre os períodos de 1950 a 1976 e de 1979 a 2000 nas sub-bacias localizadas no Alto São Francisco, o incremento na precipitação média no segundo período resultou, em relação ao primeiro, em grande aumento na vazão específica média de longa duração, comportamento que pode ser explicado pelo fato de que, sendo as precipitações médias nessas sub-bacias já elevadas em relação às das outras sub-bacias, o solo permanece com umidade também mais elevada durante grande parte do ano, com o que, por ocasião da ocorrência das precipitações, maior parcela dessas é convertida, seja em escoamento superficial ou em escoamento subterrâneo, com a ressalva de que ambos acarretarão aumento na vazão específica média, fato também relacionado com a impermeabilização devido à intensa urbanização evidenciada nessas sub-bacias.

Comportamento similar ao da vazão específica média de longa duração também pode ser evidenciado no coeficiente de deságüe (Figura 6) cujo crescimento, com o aumento do total precipitado, está diretamente associado ao fato de que, com o aumento do total precipitado, menor parcela do coeficiente de deságüe será convertida em evapotranspiração, acarretando maior proporção da precipitação convertida em escoamento no rio.

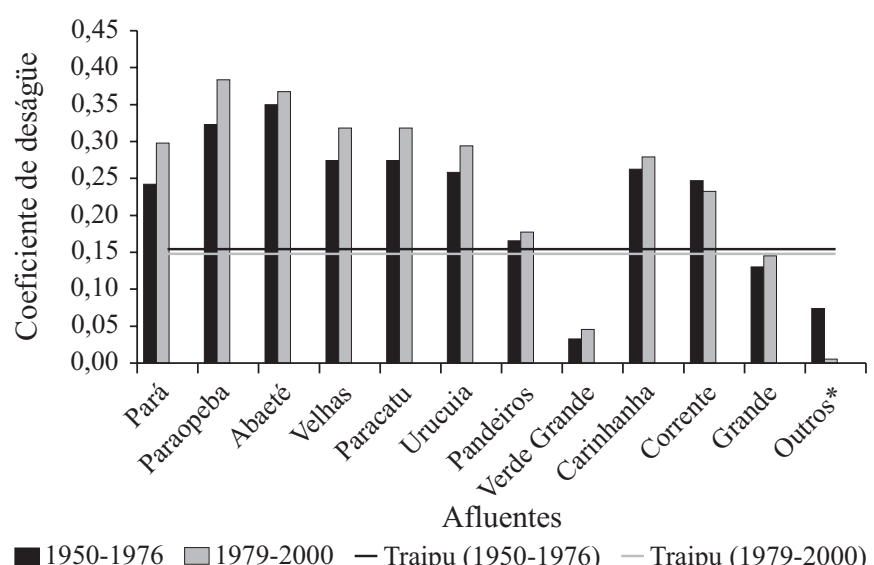
${ }^{*}$ ( ) Contribuição da área de drenagem não abrangida pelos afluentes estudados e 0 efeito das ações antrópicas

Figura 6. Coeficiente de deságüe nos principais afluentes e no rio principal, representado pela estação Traipu, considerando-se os períodos de 1950 a 1976 e de 1979 a 2000 
Analisando-se a Sub-Bacia do Verde Grande, que apresenta o menor coeficiente de deságüe entre as sub-bacias estudadas observou-se, no período de 1950 a 1976, que do volume total precipitado apenas 3\% atingiam a sua foz, desaguando no Rio São Francisco, com o que 97\% do total precipitado são convertidos, basicamente, em evapotranspiração. De 1979 a 2000 notou-se que o aumento do total precipitado também acarretou aumento da proporção do volume escoado (5\%), confirmando o comportamento já discutido.

Nas sub-bacias do Alto São Francisco se encontram os maiores valores do coeficiente de deságüe, de 0,35 no primeiro período (Sub-Bacia do Rio Abaeté) e de 0,38 no segundo (Sub-Bacia do Rio Paraopeba), comportamento este decorrente das maiores precipitações evidenciadas nessas áreas e da impermeabilização, no caso do Paraopeba.

A Figura 7 apresenta as proporções da contribuição real dos principais afluentes do Rio São Francisco para a formação da sua vazão, considerando-se os períodos de 1950 a 1976 e de 1979 a 2000. Analisando-se o primeiro período (Figura 7A), que representa uma condição sem a influência dos reservatórios de regularização e, ainda, um pequeno efeito do desenvolvimento econômico, intensificado a partir da década de 1970 na bacia (ONS, 2004), evidenciou-se que a sub-bacia com maior proporção de contribuição real para a formação da vazão do Rio São Francisco foi a do Paracatu (18,2\%), bastante superior à proporção da contribuição potencial correspondente a esta sub-bacia (10,9\%); já a SubBacia do Rio Grande, embora fosse a de maior contribuição potencial $(14,2 \%)$ apresentou, no entanto, a segunda maior contribuição real (10,9\%), ou seja, muito próxima à da SubBacia do Rio das Velhas (10,5\%), com área de drenagem ainda menor.

O comportamento correspondente às Sub-Bacias dos Rios Grande $\left(\mathrm{Ad}=78.491 \mathrm{~km}^{2}\right)$ e Paracatu $\left(\mathrm{Ad}=45.203 \mathrm{~km}^{2}\right)$ pode ser compreendido pela análise do volume total anual precipitado nas áreas de drenagem dessas sub-bacias e pela magnitude da evapotranspiração potencial nessas áreas. Observou-se, na Sub-Bacia do Rio Grande, a ocorrência de precipitações médias anuais mais baixas (982 mm) em relação às da Sub-Bacia do Paracatu (1.313 mm), além de evapotranspirações potenciais na Sub-Bacia do Rio Grande, superiores às do Paracatu; portanto, o maior déficit evapotranspirométrico na Sub-Bacia do rio Grande contribui para uma conversão menor da precipitação verificada na sub-bacia para a formação da vazão do Rio São Francisco.

O efeito das baixas precipitações e altas evapotranspirações potenciais na formação da vazão do São Francisco foi ainda mais evidente na área de drenagem não abrangida pelos afluentes estudados, uma vez que esta área apresentava uma contribuição real de apenas 19,2\%, quando a contribuição potencial era de 39,6\% e a proporção dessa área em relação à bacia, de 53,7\%.

Analisando-se o período de 1979 a 2000 (Figura 7B), observou-se crescimento na contribuição real em todas as sub-bacias estudadas em relação ao primeiro período, sendo este crescimento em média de 22,3\%, exceto na área não abrangida pelos afluentes estudados, a qual apresentou redução do primeiro para o segundo período, de 19,2 para 1,5\%; este comportamento pode

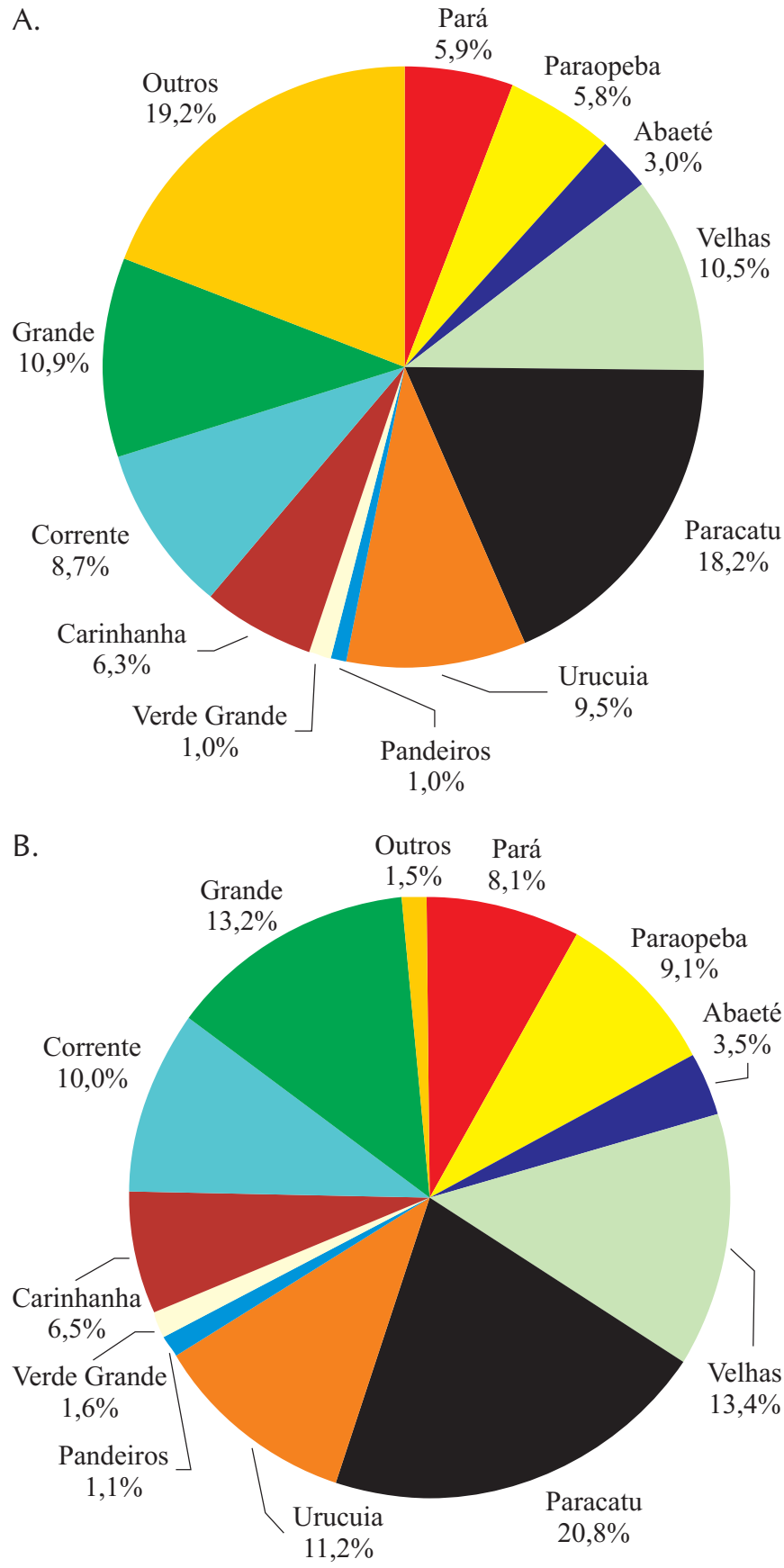

Figura 7. Proporção da contribuição real dos principais afluentes para o Rio São Francisco, considerando-se os períodos de 1950 a 1976 (A) e de 1979 a 2000 (B)

ser explicado pelo fato da evaporação ter aumentado em virtude da construção dos reservatórios de acumulação ocorridos após o ano de 1976, fazendo com que maior parcela do volume precipitado fosse convertida em evaporação.

\section{CONCLUSÕES}

1. As variáveis hidrológicas estudadas apresentaram valores médios no período de 1979 a 2000, superiores aos de 1950 a 1976.

2. As precipitações e as vazões específicas médias anuais de longa 
duração diminuíram da nascente para a foz do São Francisco.

3. As áreas de drenagem dos afluentes Pará, Paraopeba, Abaeté, Velhas, Paracatu, Urucuia, Pandeiros, Verde Grande, Carinhanha, Corrente e Grande, representando 46,3\% da área da Bacia do São Francisco, contribuíram com 81\% da sua vazão, no período de 1950 a 1976.

4. A Sub-Bacia do Rio Verde Grande foi a única com precipitação e vazão específica inferior à média da Bacia do São Francisco.

5. As sub-bacias com as maiores contribuições para a formação da vazão do Rio São Francisco, são as dos Rios Paracatu, Grande e Velhas.

\section{LITERATURA CITADA}

ANA - Agência Nacional de Águas. A evolução da gestão dos recursos hídricos no Brasil. Brasília: ANA, 2002. 64p. Edição comemorativa do dia mundial da água

ANEEL - Agência Nacional de Energia Elétrica. Atlas hidrológico brasileiro - Versão 1.0. Brasília: ANEEL, 1998. CD-Rom

Brasil. Plano Nacional de Recursos Hídricos. Documento base de referência. Brasília: MMA/SRH/ANA, 2003. 373p.

Chaves, H. M. L.; Rosa, J. W. C.; Vadas, R. G.; Oliveira, R. V. T. Regionalização de vazões mínimas em bacias através de interpolação em sistemas de informações geográficas. Revista Brasileira de Recursos Hídricos, Porto Alegre, v.7, n.3, p.43-51, 2002.
Correia, M. F.; Dias, M. A. F. S. Variação do nível do reservatório de Sobradinho e seu impacto sobre o clima da região. Revista Brasileira de Recursos Hídricos, Porto Alegre, v.8, n.1, p.157-168, 2003.

Euclydes, H. P.; Sousa, E. F.; Ferreira, P. A.; Rubert, A. V.; Santos, W. L. RH 3.0 - Regionalização hidrológica; manual do programa. Viçosa: DEA/UFV; Brasília: MMA; Belo Horizonte: RURALMINAS, 1999. 149p.

Ioris, A. A. R. Water resource development. In: São Francisco river basin (Brazil): Conflicts and management perspectives. International Water Resources Association, Aberdeen, v.26, n.1, p.24-39, 2001.

ONS; FAHMA; DREER. Estimativa das vazões para atividade de uso consuntivo da água nas principais bacias do sistema interligado nacional. In: Braga, R. S.; Gomes, M. P. (coord.). Metodologia e resultados consolidados. [S.l.: s.n.], 2004. 209p. Relatório Final

Rodriguez, F. A.; Holtz, G. P. Subprojeto 4.5.A - Diagnóstico analítico da bacia e sua zona costeira. In: ANA; GEF; PNUMA; OEA. Projeto gerenciamento integrado das atividades desenvolvidas em terra na bacia do São Francisco. Viçosa, 2003. 190p. Relatório Final

Rodriguez, R. D. G. Metodologia para estimativa da demanda e disponibilidades hídricas: Estudo de caso para a bacia do $\mathrm{Pa}$ racatu. Viçosa: UFV, 2004. 90p. Dissertação Mestrado

Tucci, C. E. M. (Org.). Hidrologia: Ciência e aplicação. 2.ed. Porto Alegre: UFRGS/ABRH, 2000, 943p. 